\title{
The ShakeMaps of the Amatrice, M6, earthquake
}

\author{
LiCIA FAENZA*, VALENTINO LAUCIANI, AlBERTO MiCHELINI \\ Istituto Nazionale di Geofisica e Vulcanologia, \\ Centro Nazionale Terremoti, Italy \\ * licia.faenza@ingv.it
}

\begin{abstract}
In this paper we describe the performance of the ShakeMap software package (Wald et al., 1999; Worden and Wald, 2016) obtained from the fully automatic procedure to estimate ground motions, based on manually revised location and magnitude, during the main event of the Amatrice sequence with special emphasis to the M6 main shock, that struck central Italy on the 24th August 2016 at 1:36:32 UTC.

Our results show that the ShakeMap procedure we developed in the last years, with real-time data exchange among those institutions acquiring strong motion data, produces a reliable and useful description of the ground motion experienced throughout a large region in and around the epicentral area.

The prompt availability of the rupture fault model, within three hours after the earthquake occurrence, provided a better description of the level of strong ground motion throughout the affected area. Progressive addition of station data and manual verification of the data insures improvements in the description of the experienced ground motions. In particular, comparison between the MCS (Mercalli-Cancani-Sieberg) intensity shakemaps and preliminary field macroseismic reports show overall agreement within the limitations imposed by the station geometry. Finally the overall spatial pattern of the ground motion of the main shock is consistent with reported rupture directivity toward NW and reduced levels of ground shaking toward SW probably linked to the peculiar source effects of the earthquake.
\end{abstract}

\section{INTRODUCTION}

$\mathrm{S}$ hakeMap is a software package [Wald et al. 1999a; Worden et al. 2010, Worden and Wald, 2016] that can be used to generate maps of ground shaking for various peak ground motion (PGM) parameters, including the peak ground acceleration (PGA), peak ground velocity (PGV), and spectral acceleration response (PSA) at $0.3 \mathrm{~s}, 1.0 \mathrm{~s}$ and $3.0 \mathrm{~s}$, and instrumentally derived intensities.

The primarily aim of the implementation of the ShakeMap code [Michelini et al., 2008] at the Istituto Nazionale di Geofisica e Vulcanologia (INGV; National Institute of Geophysics and Volcanology) is to support the Dipartimento della Protezione Civile (DPC; Civil Protection Department) providing a first order assessment of the experienced ground shaking to better direct the rescue teams and planning the emergency responses in the first few hours following a damaging earthquakes.

At its core, ShakeMap is a seismologically based interpolation algorithm that exploits the available data of the observed ground motions and the available seismological knowledge to produce maps of ground motion at local and regional scales. Of particular importance when calculating the maps is the availability of observed data to accurately reproduce the ground shaking experienced, especially in the near source.

Thus, in addition to data that are essential to derive realistic and accurate results, the fundamental ingredients for obtaining accurate maps are: the ground-motion prediction equation (GMPE), as a function of distance at different periods, and for different magnitudes; and realistic descriptions of the amplifications 
that the local site geology induces on the incoming seismic wavefield; i.e., the site effects. In its current version, ShakeMap relies on regional attenuation laws and local site amplifications based on the S-wave velocities in the uppermost $30 \mathrm{~m}$ (VS30) to generate its PGM maps [Michelini et al., 2008].

In this report, we start with a chronicle of the generation of the shakemaps for two main events of the sequence that struck Central Italy the 24 August 2016 between the towns of Amatrice and Norcia [Scognamiglio et al., this issue; Michele et al., this issue] and we conclude with a comment on the procedure we adopted. The main shock caused severe damage in the small towns in Central Italy, including Amatrice and Accumuli and in dozens of villages located along the river Tronto and almost 300 casualties [Azzaro et al, this issue]. The shaking was felt throughout central Italy.

In the recent past, moderate seismic events struck this area (Gubbio 1984, Mw 5.6; Colfiorito 1997, Mw 6.0; Norcia 1979, Mw 5.9; L'Aquila 2009, Mw 6.1), all with focal mechanisms consistent within the regional NE-SW extension of the stress field. The main shock of the Amatrice sequence occurred along a fault alignment which extends from Mt. Vettore to Mt. Gorzano, which is external (to the E) of the tectonic alignment that develops from Gubbio to Colfiorito and, to the south, extends to the area struck by the 2009 L'Aquila sequence.

As of October 6, 2016, shakemaps have been determined for a total of 74 earthquakes with $\mathrm{M}>=3.5$.

\section{THE AUGUST 24, 2016 ML 6.0 EARTHQUAKE}

In this section, we present a concise description of the evolution of the ShakeMap determination for the August 24, 2016, Ml 6.0 earthquake.

i) The automatic final earthquake location (origin time, 01:36:32 UTC; latitude, $42.69^{\circ} \mathrm{N}$; longitude, $13.2^{\circ} \mathrm{E}$; depth, $4 \mathrm{~km}$ ) was available within 5 minutes of the origin time (01:41:37 UTC). ii) The manually revised location became available 17 minutes (1:53 UTC) after the origin time, with a similar location $(42.71 \mathrm{~N}, 13.22$ E), and depth $(4 \mathrm{~km})$.

iii) For the magnitude estimation, the first automatic determination, which became available within about $5 \mathrm{~min}$ from the origin time, was ML 6.0 The manual revision, which was available after $12 \mathrm{~min}$, confirmed the same value. The first moment magnitude was available 1.5 $\mathrm{h}$ later, as Mw 6.0 [Scognamiglio et al., 2009; Scognamiglio et al., this issue].

iv) The first shakemap based on the automatic location and magnitude became available at 1:43:16 UTC. This map included only the first data available and lacks of near epicenter stations.

v) The first map that included the available RAN ("Rete Accelerometrica Nazionale" managed by the Department of Civil Protection, DPC) strong motion data and the more distant broadband data of the Italian seismic network (RSN) including the local networks of the Universities of Genova and Trieste, OGS, AMRA, among others became available at 02:27 UTC, $\sim 46$ minutes after the automatic location and 33 minutes after the revised location (version 3 , figure 1 ). The spatial coverage of the epicentral area is somewhat denser though the near finite source area is still only partly covered (only NRC and RQT station PGM data became available).

vi) Based on the time domain moment tensor solution [Scognamiglio et al., this issue], the scaling laws [Wells and Coppersmith, 1994], and the geology, with the analysis of the active tectonic structures in the area and their orientation, the first maps with the fault included (version 5) were published at 04:39 UTC, about 3 hours after the earthquake occurrence (figure 2). This map better constrains the shaking in the epicentral area by taking into account the fault finiteness. Insertion of the fault is based, however, on a manual procedure which requires the availability of the manually revised moment tensor and rapid selection of one of the rupture planes. 

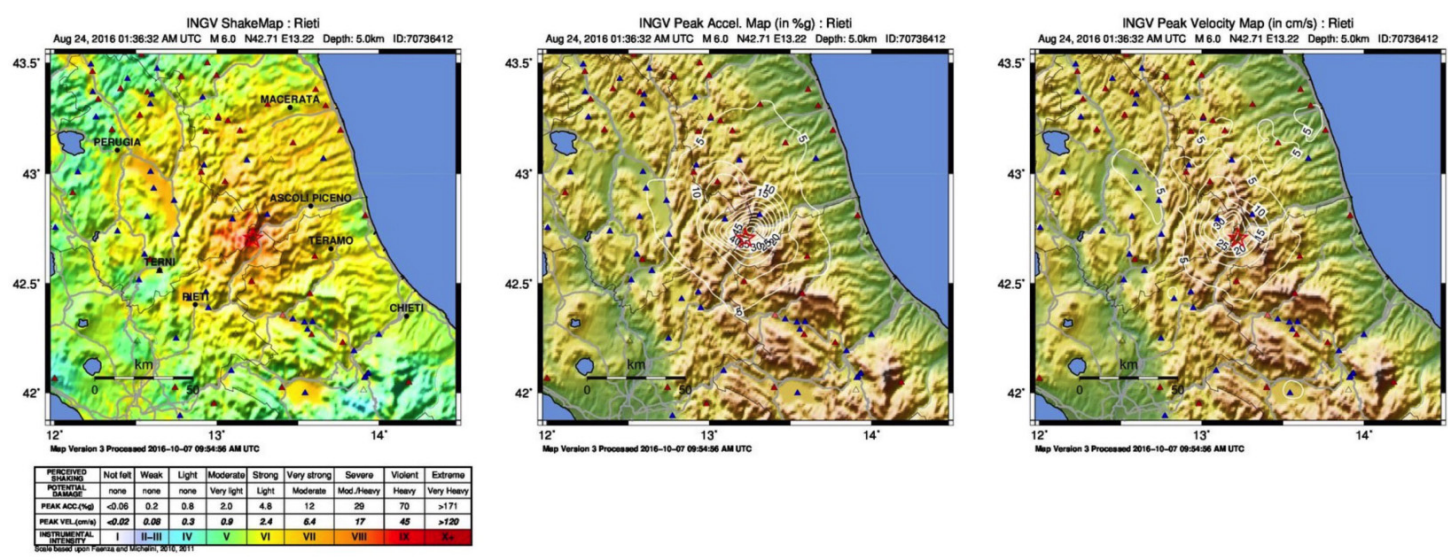

Figure 1. The Shakemaps of the main shock using automatic processing for the INGV PGM data and the PGM data provided by DPC. Left: MCS derived instrumental intensity; Center: PGA; Right: PGV.
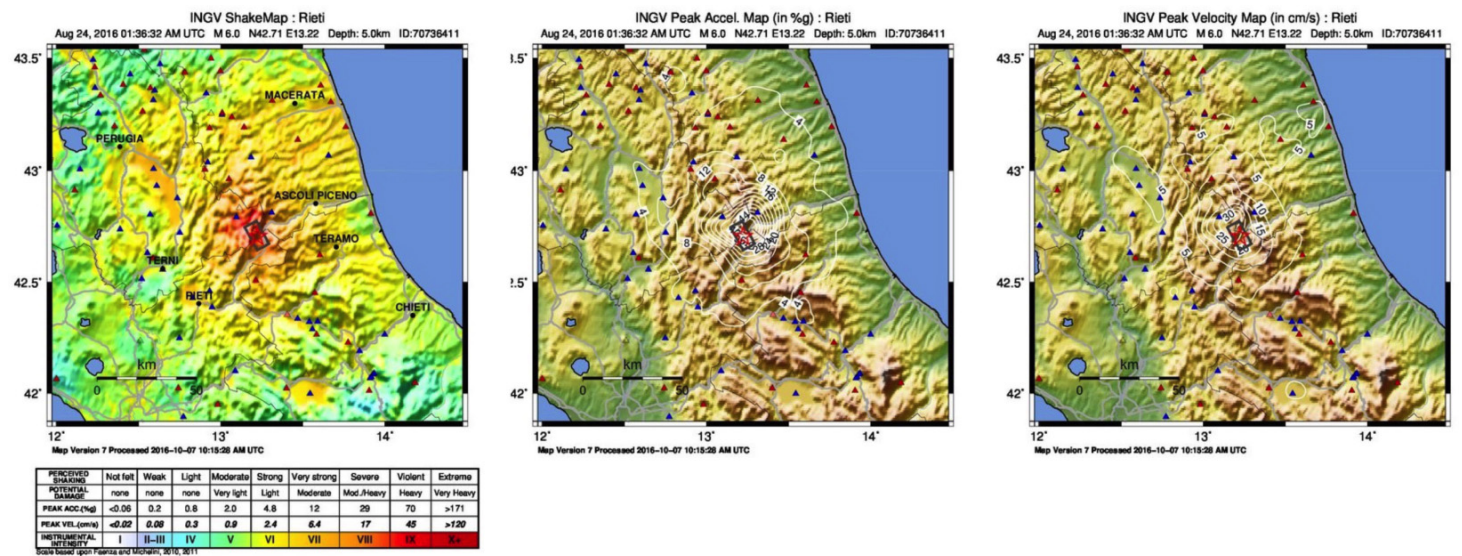

Figure 2. The Shakemaps of the main shock as in Figure 1 after inserting the fault. Left: MCS derived instrumental intensity; Center: PGA; Right: PGV.

In the following days, the maps were updated with more close-in and distant stations and the Mercalli Intensity instrumentally derived scale of Wald et al. [1999] was replaced by the MCS [Mercalli-Cancani-Sieberg; Sieberg, 1930] intensity scale calibrated for Italy (Faenza and Michelini, 2010, 2011). This second change was adopted because MCS intensities have been found more informative to non-expert audiences unfamiliar with instrumental ground motion parameters. More specifically, in the INGV ShakeMap implementation [Michelini et al., 2008], the instrumentally derived intensity values are derived from the conversion of PGM into intensity values as proposed by Wald et al. [1999b]. This regression, however, is based on the Mercalli Modified scale calibrated using intensity and PGM data collected in California. In Italy, the analysis of historical seismicity through the use of the macroseismic intensity data has a long tradition and the MCS intensity scale has been long adopted. To attain homogeneity between the instrumentally derived intensity maps and the observed Italian macroseismic intensities, new regression relations between PGM and MCS intensity 


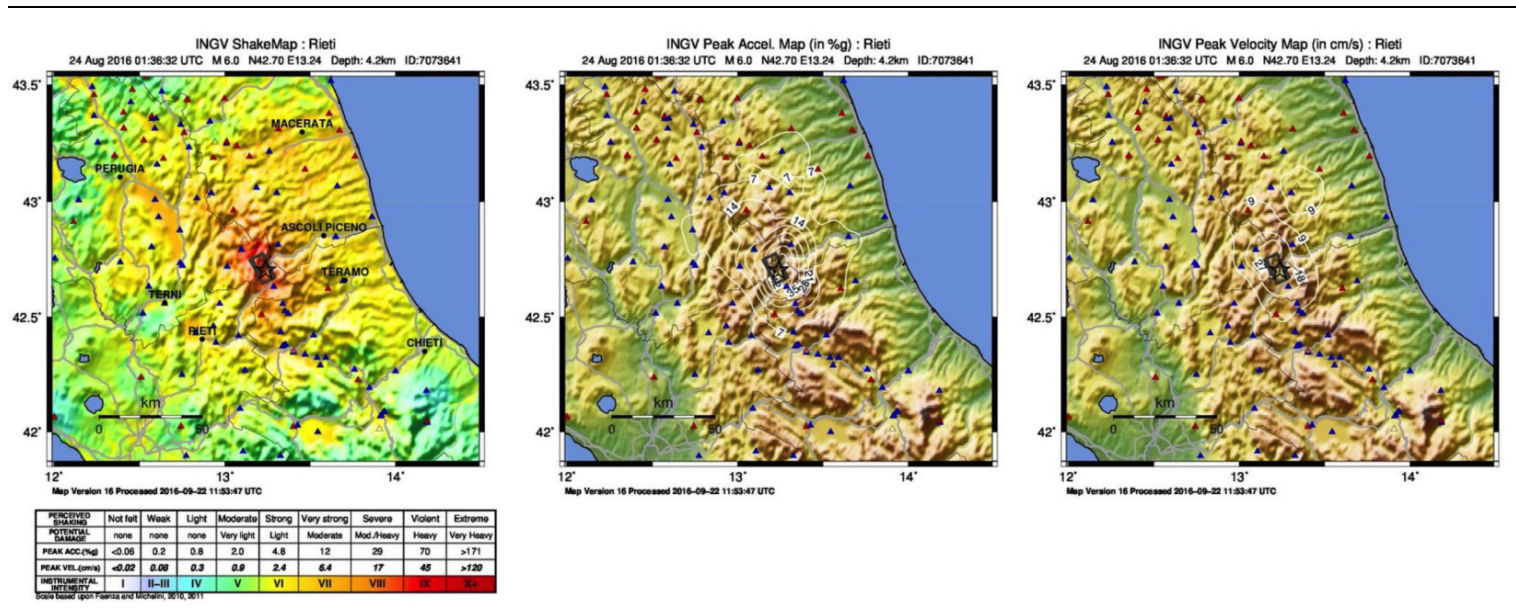

Figure 3. The Shakemaps of the main shock using the revised data obtained from the engineering strong motion DB (http://esm.mi.ingv.it). Left: MCS derived instrumental intensity; Center: PGA; Right: PGV.

data were proposed by Faenza and Michelini [2010, 2011] but never implemented into the ShakeMap procedure at INGV since it was sought to maintain consistency with similar instrumental values elsewhere worldwide. These new relations for MCS were inserted in ShakeMap starting with the mainshock of this sequence to better support local needs in Italy. The shakemaps are by their nature determined very rapidly right after an earthquake using automatic procedures. In the following days, however, new PGM data became available determined from manually revised waveforms. At INGV the strong motion data are verified and archived in the Engineering Strong Motion DB (ESM; http://esm.mi.ingv.it) together with the associated PGM parameters. Therefore on September 22, 2016, once the revised data became available we replaced the PGM readings and re-determined the maps (figure 3).

Overall, this procedure allows a progressive improvement in the quality of the shakemaps as additional data become available and manual intervention is performed.

In figure 4 we have summarised the improvements obtained by calculating the differences (for PGA) between the final shakemaps shown in figure 3 and the maps obtained with the automatic processing (figures 2 and 1). In summary, we note that $i$ ) the addition of the AMT station data condition strongly the values of PGA at the southern end of the rupture plane and ii) including the fault is important to improve and extend the pattern of ground motion near and above the fault.

The shakemaps shown in figures 1-3 show the maps of the main shock as they result at the end of the steps outlined above. The largest values of the ground motion occur next or above the fault plane as resulting from the largest values of acceleration recorded by the three closest stations (AMT, RQT and NRC) that all recorded values around $40 \% \mathrm{~g}$. This whole area featured values of PGV on the horizontal components larger than $20 \mathrm{~cm} / \mathrm{s}$ (intensity level VIII). One important feature of the PGA and PGV maps is that relatively large accelerations have been recorded from NW to $\mathrm{NE}$ of the earthquake epicenter (see the $7 \% \mathrm{~g}$ contour line) when compared to those recorded SE and especially to the SW. This pattern is likely dependent on the source directivity observed for the main shock both from the raw data [INGV-ReLUIS Working Group, 2016] and from the preliminary finite fault inversion results using strong motion data [Tinti et al, 2016]. 

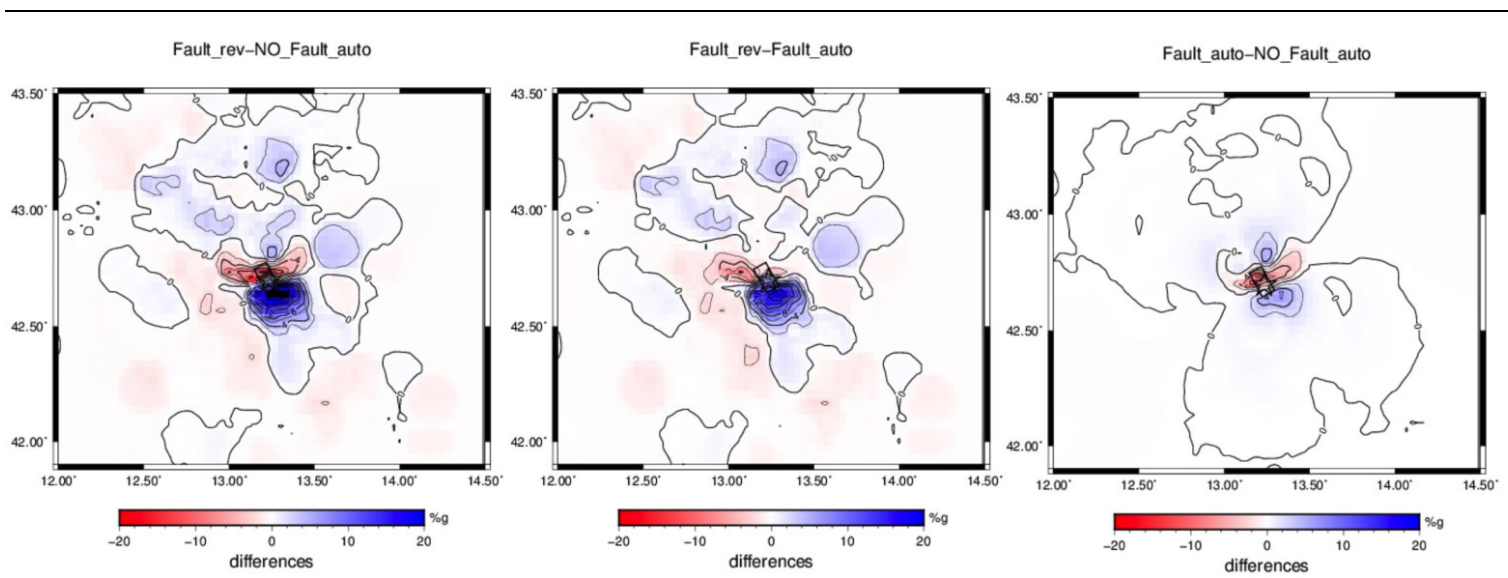

Figure 4. Differences between the different PGA shakemaps. Left: final shakemap with revised data and fault map compared with automatically processed data and no fault; center: final shakemap with revised data and fault map compared with automatically processed data and fault inserted; right: shakemap with fault and automatically processed data compared with the same data but no fault.

\section{DISCUSSION}

In August 2016, a seismic sequence struck the Apennine in Central Italy, an area that has a long history of destructive earthquakes, as known from historical and macroseismic analysis [Locati et al, 2015]. In this study, we have described the determination and the progressive updating of the shakemaps of the main shock as additional and more accurate information became available.

In our experience, the inclusion of observed data is of fundamental importance for the calculation of shakemaps. Indeed, the quantification of the shaking near the epicentre using only the PGM prediction equations complemented with site-effect corrections is difficult and prone to macroscopic errors and bias [Faenza et al. 2011; Lauciani et al, 2012]. Moreover, for larger earthquakes that saturate the recordings of the velocimeters at and near the epicenter, the accuracy of the shakemaps depends also on the prompt availability of strong-motion data, which, for the Amatrice main shock, become available shortly after its occurrence. We have found that the area stricken by the sequence has in general a dense enough station coverage to produce reasona- bly accurate maps of the strong ground shaking. The installation of the temporary stations in the epicentral area improved, however, the coverage for the subsequent events.

Comparing figures 1 and 3, it is possible to see the improvement in the quantification of the ground shaking with the inclusion of the source model and new review data (see figure 4 for the differences in terms of PGA). The first preliminary shakemap (figure 1) remained online for only 3 hours. Figure 2 shows a different pattern in the near-source shaking because of the adoption of the Joyner-Boore distance measure from the fault location, leading to an underestimation of the PGM values in the near source. We note also that this time, we have not encountered the time delay experienced previously in the strong motion data exchange since both the RAN data and the INGV data were readily available.

Since the intensity scale in our maps adopts the relations obtained from the regression between PGM parameters and the MCS intensity values of Faenza and Michelini (2010, 2011), we have compared the final shakemaps with the preliminary macroseismic maps available at the time of writing this work. In figure 5 we show the two maps represented using the same color scale. We note 

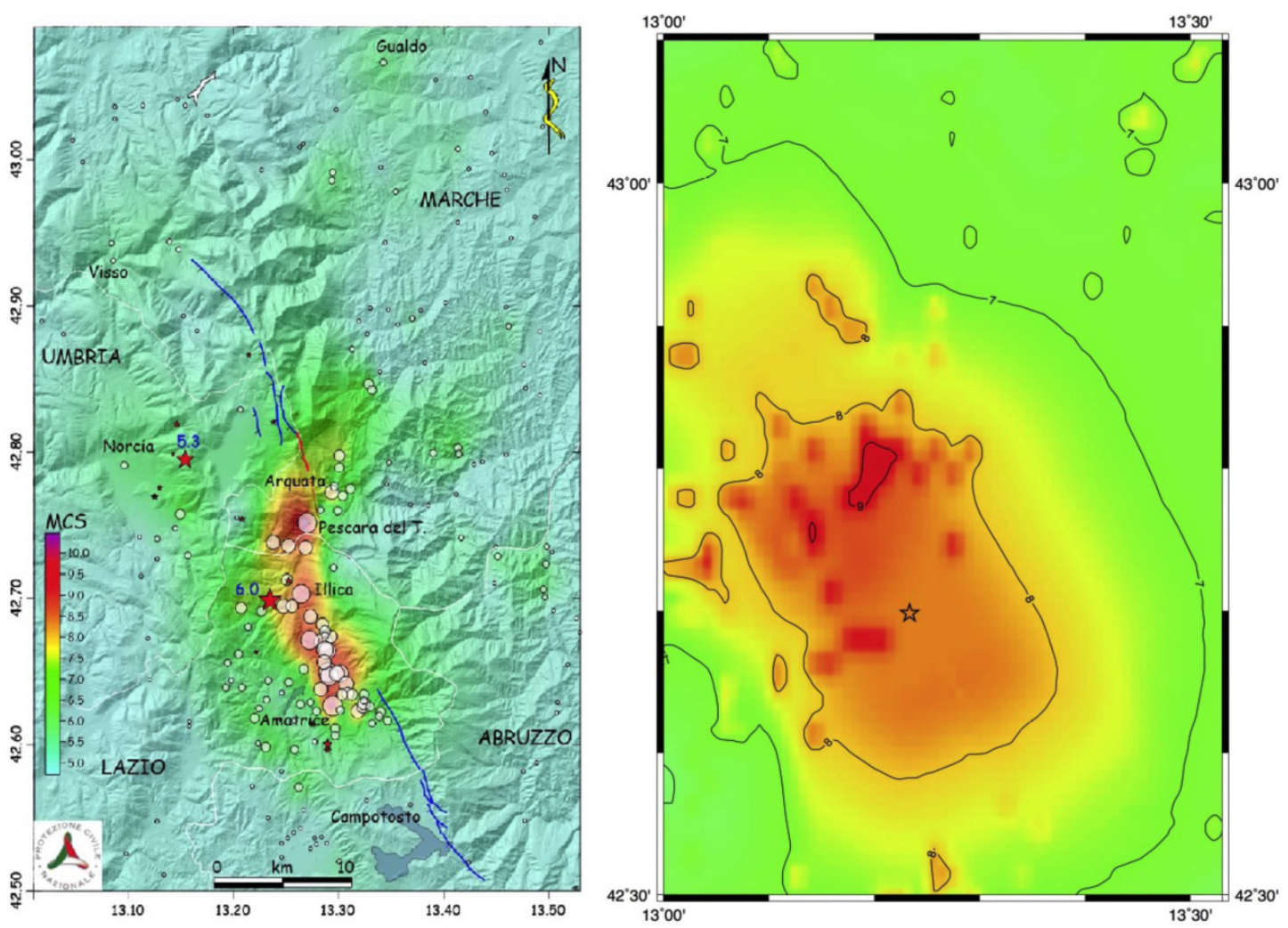

Figure 5. Comparison between the reported macroseismic intensities and the estimated intensities obtained using Shakemap represented using the same color palette. Left: preliminary macroseismic map compiled by the field macroseismic teams (from "Rapporto sugli effetti macrosismici del terremoto del 24 Agosto 2016 di Amatrice in scala MCS" a cura di P. Galli e E. Peronace, Coordinamento del rilievo macrosismico MCS a cura di P. Galli e A. Tertulliani, 2016). Right: MCS intensity values obtained with the final shakemap updated with the manually revised data.

that the MCS intensity shakemap although much blurred since it relies on essentially three main data points in the near fault region (AMT, $\mathrm{NRC}$, and RQT) can nevertheless provide a very first information on the ground shaking in the near fault region. For example, and by simply determining the population within e.g. the level VIII MCS, it is possible to obtain very rapidly an initial estimate of the population exposed to that intensity level as has been provided by the USGS that publishes the PAGER estimates (Earle et al., 2009). For the Amatrice earthquake we found that by using the MCS VIII contour as polygonal line within which to extract the population from the LandScan population DB (http://web.ornl.gov/sci/landscan/), it would have resulted almost immediately that $\sim 10,000$ people would have been exposed to strong ground shaking. Similar estimates can be done for lower intensity levels.

\section{CONCLUSIONS}

Our analysis has shown that for the M6 Amatrice earthquake of August 24, 2016, the shakemaps produced by INGV

i) became available within a few minutes of the main shock and they already had an amount of data that insured a relatively good assessment of the ground shaking experienced in the Amatrice and nearby villages and towns; 
ii) inclusion of the finite fault within $\sim 3$ hours of the main shock contributed to improve the accuracy of the maps;

iii) inclusion of additional data as they become progressively available is important to improve the quality of the maps;

iv) inclusion of thoroughly reviewed data is equally important to avoid that the maps could be possibly contaminated by processing errors always present in automatic procedures;

v) comparison between the MCS intensity shakemaps and a preliminary map of the macroseismic report compiled by the teams that have evaluated the macroseismic intensity in the field indicates a remarkable similarity between estimated and reported intensities.

vi) the pattern of spatial ground motion obtained is consistent with the preliminary reports that indicate rupture directivity toward NW and relatively reduced levels of ground motion toward SW from the earthquake source.

\section{REFERENCES}

[Azzaro et al., 2016] Azzaro R., A. Tertulliani, F. Bernardini, R. Camassi, S. Del Mese, E. Ercolani, L. Graziani, M. Locati, A. Maramai, V. Pessina, A. Rossi, A. Rovida, P. Albini, L. Arcoraci, M. Berardi, C. Bignami, B. Briquela, C. Castellano, V. Castelli, S. D'Amico, V. D'Amico, A. Fodarella, I. Leschiutta, A. Piscini, M. Sbarra. The Amatrice 2016 earthquake: macroseismic survey in the damage area and preliminary EMS intensity assessment, Annals of Geophysics, 59, Fast Track 5, doi:10.4401/ag-7203.

[Earle et al., 2009] Earle, P.S., Wald, D.J., Jaiswal, K.S., Allen, T.I., Marano, K.D., Hotovec, A.J., Hearne, M.G., and Fee, J.M (2009). Prompt Assessment of Global Earthquakes for Response (PAGER): A system for rapidly determining the impact of global earthquakes worldwide. U.S. Geological Survey Open-File Report 2009-1131.
[Faenza and Michelini, 2010] Faenza L. and A. Michelini, Regression analysis of MCS intensity and ground motion parameters in Italy and its application in ShakeMap, Geophys. J. Int, 180(3), 1138-1152, doi:10.1111/j.1365246X.2009.04467.x.

[Faenza et al., 2011] Faenza, L., V. Lauciani and A. Michelini (2011). Rapid determination of the shake maps for the L'Aquila main shock: a critical analysis, B. Geofis. Teor. Appl., 52, 407425 .

[Faenza and Michelini, 2011] Faenza, L., and A. Michelini (2011), Regression analysis of MCS intensity and ground motion spectral accelerations (SAs) in Italy, Geophys. J. Int, 1-16, doi:10.1111/j.1365-246X.2011.05125.x.

[INGV-ReLUIS Working Group, 2016] INGVReLUIS Working Group (2016), Preliminary study of Rieti earthquake ground motion data V5, 1-87, doi:10.13140/RG.2.2.27933.92641/1. [Available at http:/ / www. reluis. it].

[Lauciani et al., 2012] Lauciani V., L. Faenza and A. Michelini (2012), SchakeMap during the Emilia sequence, Annals of Geophysics, 55, 4, 2012; doi: 10.4401/ag-6160.

[Locati et al, 2015] Locati M., Camassi R., Rovida A., Ercolani E., Bernardini F., Castelli V., Caracciolo C.H., Tertulliani A., Rossi A., Azzaro R., D'Amico S., Conte S., Rocchetti E. (2016). DBMI15, the 2015 version of the Italian Macroseismic Database. Istituto Nazionale di Geofisica e Vulcanologia; doi:http:/ / doi.org/10.6092/INGV. IT-DBMI15.

[Michele et al., 2016] Michele M., Di Stefano R., Chiaraluce L., Cattaneo M., De Gori P., Monachesi G., Latorre D., Marzorati S., Valoroso L., Ladina C., Chiarabba C., Lauciani V. and M. Fares. The Amatrice 2016 seismic sequence: a preliminary look to the mainshock and after- 
shocks distribution, Annals of Geophysics, 59, Fast Track 5, doi:10.4401/ag-7277.

[Michelini et al., 2008] Michelini A., L. Faenza, V. Lauciani and L. Malagnini (2008). ShakeMaps implementation in Italy, Seismol. Res. Lett., 79, 688-697.

[Scognamiglio et al., 2009] Scognamiglio, L., E. Tinti, and A. Michelini (2009), Real-Time Determination of Seismic Moment Tensor for the Italian Region, Bull. Seismol. Soc. Am., 99 (4), 2223-2242.

[Scognamiglio et al., this issue] Scognamiglio L, E. Tinti, M. Quintiliani, The 2016 Amatrice seismic sequence: Fast determination of the time domain moment tensors and finite fault model analysis of the ML 5.4 aftershock, This issue.

[Sieberg, 1930] Sieberg A. (1930), Geologie der Erbbeben, Handbuch der Geophysik, 2, 4, 552555.

[Tinti et al, 2016] Tinti, E., L. Scognamiglio, A. Michelini, and M. Cocco (2016), Slip heterogeneity and directivity of the M L6.0, 2016, Amatrice earthquake estimated with rapid finitefault inversion, Geophys. Res. Lett, 1-8, doi:10.1002/2016GL071263.

[Wald et al., 1999a] Wald, D.J., Quitoriano, V., Heaton, T.H., and Kanamori, H., (1999a), Relationship between Peak Ground Acceleration, Peak Ground Velocity, and Modified Mercalli Intensity in California, Earthquake Spectra, 15 (3), p. 557-564.

[Wald et al., 1999b] Wald, D.J., Quitoriano, V., Heaton, T.H., Kanamori H, Scrivner, C.W. and Worden C.B. (1999n). Trinet 'ShakeMaps': rapid generation of peak ground motion and intensity maps for earthquakes in southern California, Earthq. Spectra, 15, 537.
[Wells and Coppersmith, 1994]. Wells D.L., and K.J. Coppersmith (1994). New empirical relationships among magnitude, rupture length, rupture width, rupture area, and surface displacement, B. Seismol. Soc. Am, 84, 974-1002.

[Worden et al., 2010 ] Worden, C.B., Wald, D.J., Allen, T.I., Lin, K., Garcia, D. and Cua G. (2010). $A$ revised ground-motion and intensity interpolation scheme for ShakeMap. B. Seismol. Soc. Am. 100, 3083-3096.

[Worden and Wald, 2016] Worden, C. B., and D. J. Wald (2016), ShakeMap Manual, version 2.0, 1-113. 